Faculty of Science

Faculty Publications

Radical Stabilization Algorithm as a Predictive Tool for Novel and Reported Noncanonical Thiele's Acid Analogues

Jun Chen, Lingxiao Lu, and Jeremy E. Wulff

2017

(C) 2017 Georg Thieme Verlag Stuttgart

This article was originally published at:

https://doi.org/10.1055/s-0036-1588583

Citation for this paper:

Chen, J., Lu, L., \& Wulff, J. E. (2017). Radical stabilization algorithm as a predictive tool for novel and reported noncanonical Thiele's acid analogues. Synlett, 28(20), 27772782. https://doi.org/10.1055/s-0036-1588583 


\section{Radical Stabilization Algorithm as a Predictive Tool for Novel and Reported Noncanonical Thiele's Acid Analogues}

\author{
Jun Chen \\ Lingxiao Lu \\ Jeremy E. Wulff* \\ Department of Chemistry, University of Victoria, \\ Victoria, BC, V8W 3V6, Canada \\ wulff@uvic.ca \\ This paper is dedicated to Professor Victor Snieckus, \\ in honour of his $80^{\text {th }}$ birthday
}

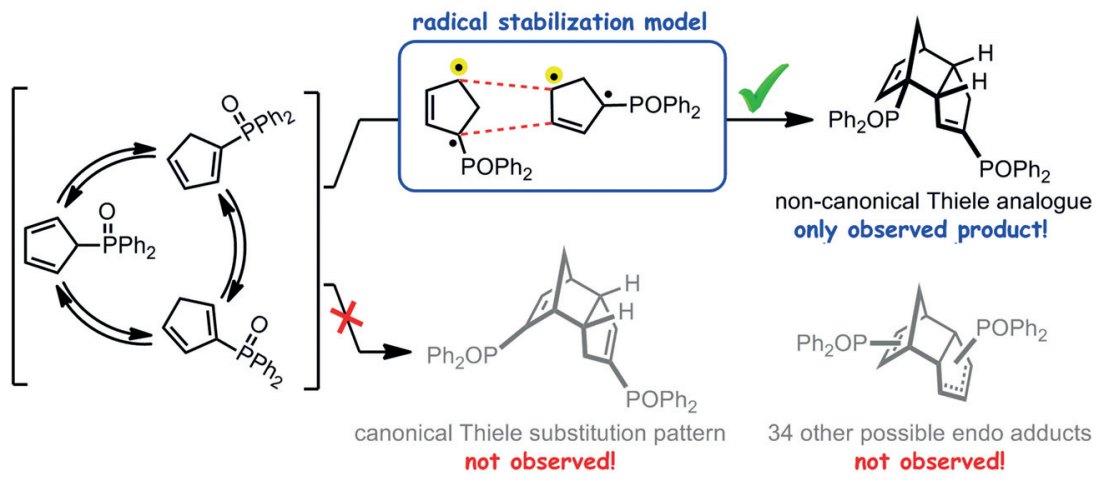

Received: 25.07.2017

Accepted after revision: 08.09.2017

Published online: 06.10.2017

DOI: 10.1055/s-0036-1588583; Art ID: st-2017-r0579-I

Abstract We recently showed that a simple radical-stabilization algorithm outperformed traditional frontier-molecular orbital methods for rationalizing the outcome of the venerable Thiele's acid (or ester) DielsAlder dimerization. In the present Communication, we describe a novel noncanonical Thiele-type dimerization of a cyclopentadiene phosphine oxide, and show that when steric factors are taken into account the radical-stabilization method once again correctly rationalizes the regiochemical outcome for the reaction. We further show that the method appears to be general for all known Thiele- and half-Thiele dimerization events.

Key words Diels-Alder reaction, Thiele's acid, predictive methods for cycloadditions

The Diels-Alder reaction is one of the most powerful methods available to synthetic chemists for the construction of complex cyclic and heterocyclic frameworks. ${ }^{1}$ Since its discovery in 1928, the reaction has been broadly applied in a diverse array of fields, including natural product synthesis, medicinal chemistry, and materials science. ${ }^{1 c, 2}$ For many simple Diels-Alder reactions, useful predictive models allow the experimentalist to reliably forecast the regiochemical outcome for the transformation. However, for more complicated Diels-Alder reactions, prediction remains a challenge and so the development of simple (i.e., noncomputationally intensive) predictive models remains an important field of research.

Thiele's acid (1a) is the principal Diels-Alder dimerization product of carboxylated cyclopentadiene (Scheme 1). While 1a and its simple ester or amide analogues have been employed in a wide range of applications (e.g., as rigid synthetic scaffolds, ${ }^{3}$ polymer precursors, ${ }^{4}$ chiral building blocks, ${ }^{5}$ molecular clefts, ${ }^{6}$ etc.), the mechanism of its formation continues to be a topic of considerable discussion.

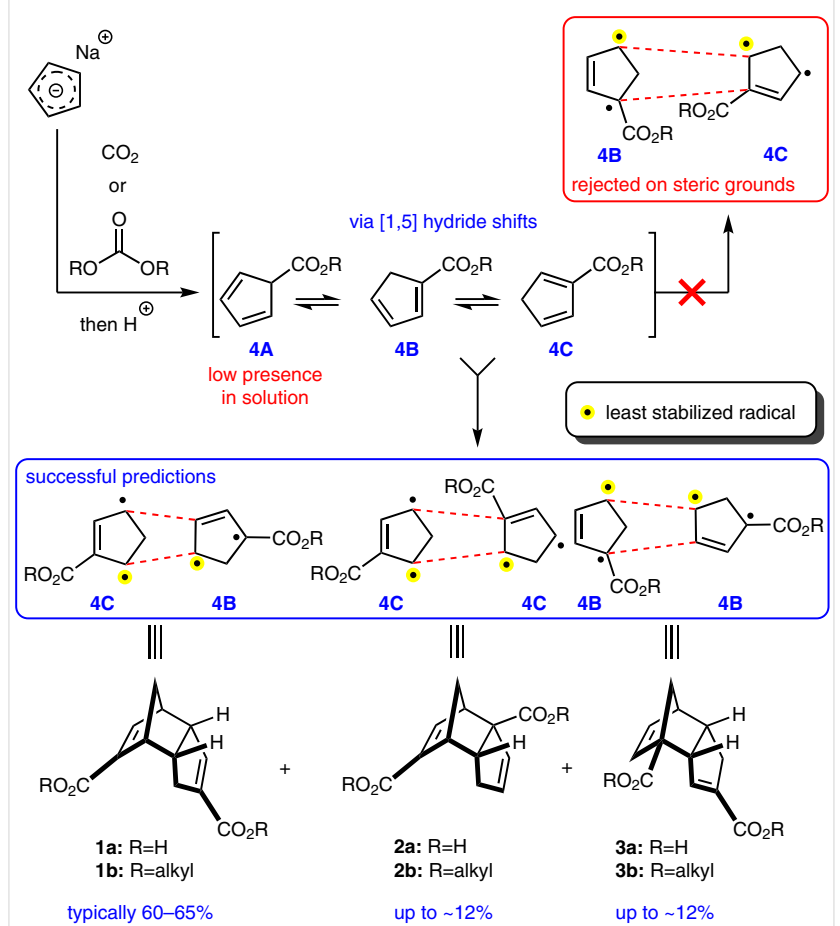

Scheme 1 Prediction of Thiele's acid or ester dimerization by radical stabilization logic. Yellow highlighting indicates the least stabilized radical for each structure.

Because rapid [1,5]-hydrogen shifts allow for facile interconversion between the monomeric substituted cyclopentadiene precursors to Thiele's acid (4A, 4B and 4C), and because these three monomers could in principle combine in a variety of ways, there are actually 72 possible products that could be envisioned for the reaction (36 endo adducts and 36 exo adducts). However, only a single major product is observed, together with two minor regioisomers (2a and 
3a). Owing to this remarkable selectivity - and to the fact that 1a is by no means the most obvious of the 72 possible products - Thiele's acid dimerization makes for a popular probe for the efficacy of cycloaddition models, and the reaction is discussed at length both in Fleming's frontier molecular orbital (FMO) texts, ${ }^{7}$ as well as in Deslongchamps' and Deslongchamps' series on bent bonds and the antiperiplanar hypothesis. ${ }^{8}$

We recently showed ${ }^{9}$ that Deslongchamps' radical stabilization arguments ${ }^{8}$ outperformed traditional FMO analysis in rationalizing the regiochemical outcome of Thiele's acid (and ester) dimerization. This model involves consideration of both the diene and dienophile coupling partners as their singlet diradical resonance forms. Alignment of the least stabilized radical $^{10}$ from each reacting species (refer to Figure S7 for details) is used to predict the outcome of the reaction. Remarkably, this simple method was successful in identifying the correct dimerization products $(\mathbf{1}, \mathbf{2}$, and $\mathbf{3})$ out of 16 possible combinations of $\mathbf{4 B}+\mathbf{4 C}$ (4A is sufficiently higher in energy than the other two isomers that it evidently does not exist at all within the reacting mixture), ${ }^{9}$ without the need for any intensive computational work. In stark contrast, alignment of the calculated orbital coefficients for the $\pi$ systems of $\mathbf{4 A}, \mathbf{4 B}$, and $\mathbf{4 C}$ (the basis for FMO analysis) failed to successfully predict any of the three products.

In some ways, the success of diradical methods in predicting the outcome of Diels-Alder reactions should hardly be surprising, given that Dewar and others have long argued for the existence of diradical (or at least 'radicaloid') character in the transition states of Diels-Alder couplings and other pericyclic reactions. ${ }^{11-13}$ Indeed, Dewar wrote 30 years ago that ' $\mathrm{t}$ ] he regioselectivities and rates of DielsAlder reactions can be predicted on this basis, more simply and more reliably than they can in terms of frontier molecular orbital theory. ${ }^{11}$ The central problem, though, has always been that for most cycloadditions only a few possible regiochemical outcomes can be envisioned, and most predictive models (FMO analysis, resonance considerations, diradical arguments, etc.) are successful in identifying the same, correct outcome (which is almost always known ahead of time anyway).

By contrast, the large variety of possible homo- and heterodimerization events that could potentially occur for species like $\mathbf{4 A - C}$, coupled with the fact that the identities of the minor regioisomers resulting from dimerization (i.e. 2 and 3 ) were often incorrectly reported in the literature prior to our recent structural characterization efforts ${ }^{6}$ (suggesting that the correct structures would not have been known to the earlier proponents of different predictive models) means that Thiele-type dimerizations can provide a uniquely effective testing set for the predictive power of various models. While we successfully exploited this testing set in our recent study ${ }^{9}$ we also recognized that it would be more valuable if it could be expanded to include more regiochemical diversity.

In the current Communication, we contribute to this increased diversity by describing the synthesis of a novel phosphine oxide containing dimer, and showing spectroscopically that the regiochemical outcome for this reaction differs from that leading to the parent Thiele's acid. We further show the application of the radical-stabilization model to the successful prediction of regiochemistry for this and related noncanonical Thiele-type dimerizations, i.e., those in which different substitution patterns from 1a are observed in the product.

Our first challenge lay in accessing a novel, noncanonical Thiele acid analogue. In previous synthetic work, we showed that cyclopentadiene esters dimerize analogously to cyclopentadiene carboxylates, affording an equivalent collection of regioisomers (i.e., $\mathbf{1 b}, \mathbf{2 b}$, and $\mathbf{3 b}$ ) albeit with somewhat altered product ratios. ${ }^{6}$ Ketones behave similarly, at least to the extent of producing major products analogous to $\mathbf{1 .}^{6,14}$ In order to achieve different substitution patterns, we reasoned that we would have to employ more dramatically different electron-withdrawing groups.

To this end, we treated sodium cyclopentadienylide with diphenylphosphinic chloride (5a) to give a mixture of substituted cyclopentadienes $\mathbf{6}$. Consistent with the previously reported data for $\mathbf{4}$, our analysis of an NMR spectrum for 6 (see Supporting Information for spectral data) revealed mostly isomer $\mathbf{6 B}$, along with a smaller quantity of a minor species that we assigned as 6C. No signals corresponding to $\mathbf{6 A}$ were observed.

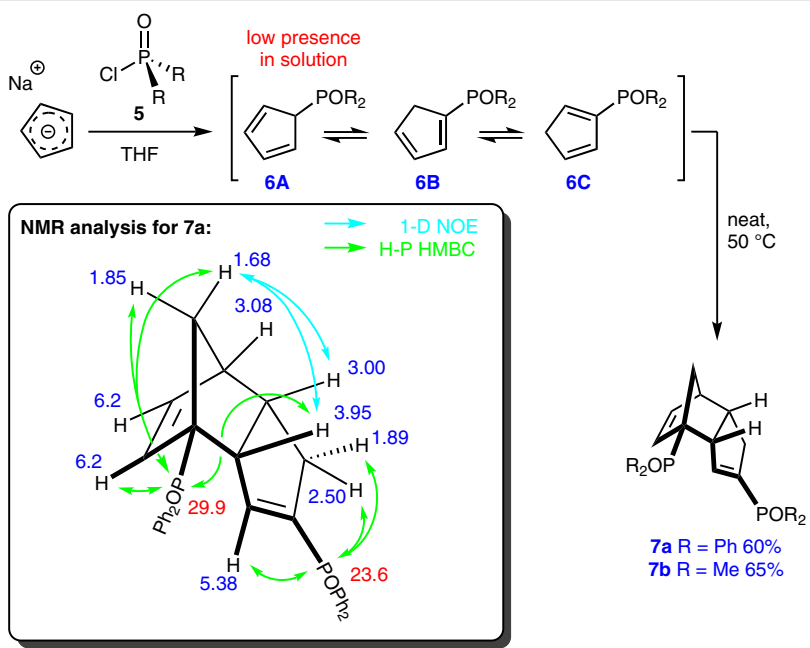

Scheme 2 Synthesis of noncanonical Thiele's acid analogues incorporating phosphine oxide groups and selected NMR data for product 7a. Values in blue indicated ${ }^{1} \mathrm{H}$ NMR shifts. Values in red indicate ${ }^{31} \mathrm{P}$ NMR shifts. 
Dimerization of $\mathbf{6}$ was effected by heating the neat mixture at $50{ }^{\circ} \mathrm{C}$. A compound which clearly bore a different substitution pattern from that of $\mathbf{1}$ was obtained as the only isolable regioisomer. We collected an extensive series of 1D and 2D NMR spectra for the isolated compound $\left({ }^{1} \mathrm{H},{ }^{13} \mathrm{C}\right.$, COSY, HMQC, ${ }^{31} \mathrm{P}$ HMBC, 1D NOE). ${ }^{31} \mathrm{P}$ HMBC experiments were particularly useful in assigning the product as $\mathbf{7 a}$ (Scheme 2). ${ }^{15}$ For example, long-range couplings from the phosphorous at $\delta=23.6 \mathrm{ppm}$ to the alkene proton at $\delta=$ $5.38 \mathrm{ppm}$ as well as to the methylene protons at $\delta=2.50$ and $1.89 \mathrm{ppm}$ were key to assigning the regiochemistry of the Eastern hemisphere of the product. Similarly, longrange couplings from the phosphorus at $\delta=29.9 \mathrm{ppm}$ (to both bridge protons at $\delta=1.68$ and $1.85 \mathrm{ppm}$, to the downfield methine proton at $\delta=3.95 \mathrm{ppm}$, and to the alkene proton at $\delta=6.2 \mathrm{ppm}$ ) were very helpful in assigning the structure of the norbornene moiety. 1D NOE data confirmed the endo ring architecture. Compound $\mathbf{7 a}$ is analogous to a minor regioisomer (3a and $\mathbf{3 b}$ ) in Thiele's acid or ester dimerization. Clearly then, the presence of the phosphine oxide functional group is exerting a significant control over the reaction outcome.

To probe this effect, we considered all possible pairings of 6B and 6C (see Supporting Information Figure S4 for illustrations of all 16 possible dimerizations; couplings involving $\mathbf{6 A}$ were discounted in view of the apparent absence of this species from the reaction mixture). As shown in Figure 1, alignment of the least stabilized radical (as identified by the algorithm described here) in each case predicts only four electronically favoured combinations

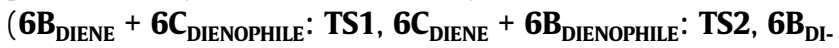
ENE $+6 B_{\text {DIENOPHILE: }}$ TS3 and $6 C_{\text {DIENE }}+6 C_{\text {DIENOPHILE: }}$ TS4). Since it is well-known that transition-state geometries and steric effects are important in determining the outcome of DielsAlder reactions, ${ }^{16}$ we next considered these factors in our model. TS1 would clearly be rejected on steric grounds, owing to the formation of two adjacent quaternary centres. TS2 - which is analogous to the combination that leads to $\mathbf{1 a}$ and $\mathbf{1 b}$ for the acid and ester cases - would in this case suffer from substantial crowding due to the need to bring four phenyl rings into close proximity with one another. Thus, the tetrahedral geometry of the phosphine oxide substituent would be expected to significantly limit the accessibility of this transition state.

Between TS3 and TS4, it is less obvious which one would be favoured. However, rotation of the association complexes reveals that TS4 suffers from steric repulsion between the phenyl substituents and the protons on the cyclopentadiene ring (blue in Figure 1). ${ }^{17}$ Thus, TS3 is the least sterically hindered combination among the four electronically permitted pairings of monomers and would therefore be expected to best facilitate the dimerization reaction, even though it leads to a relatively congested product. Significantly, TS3 would uniquely (and correctly!) pre-
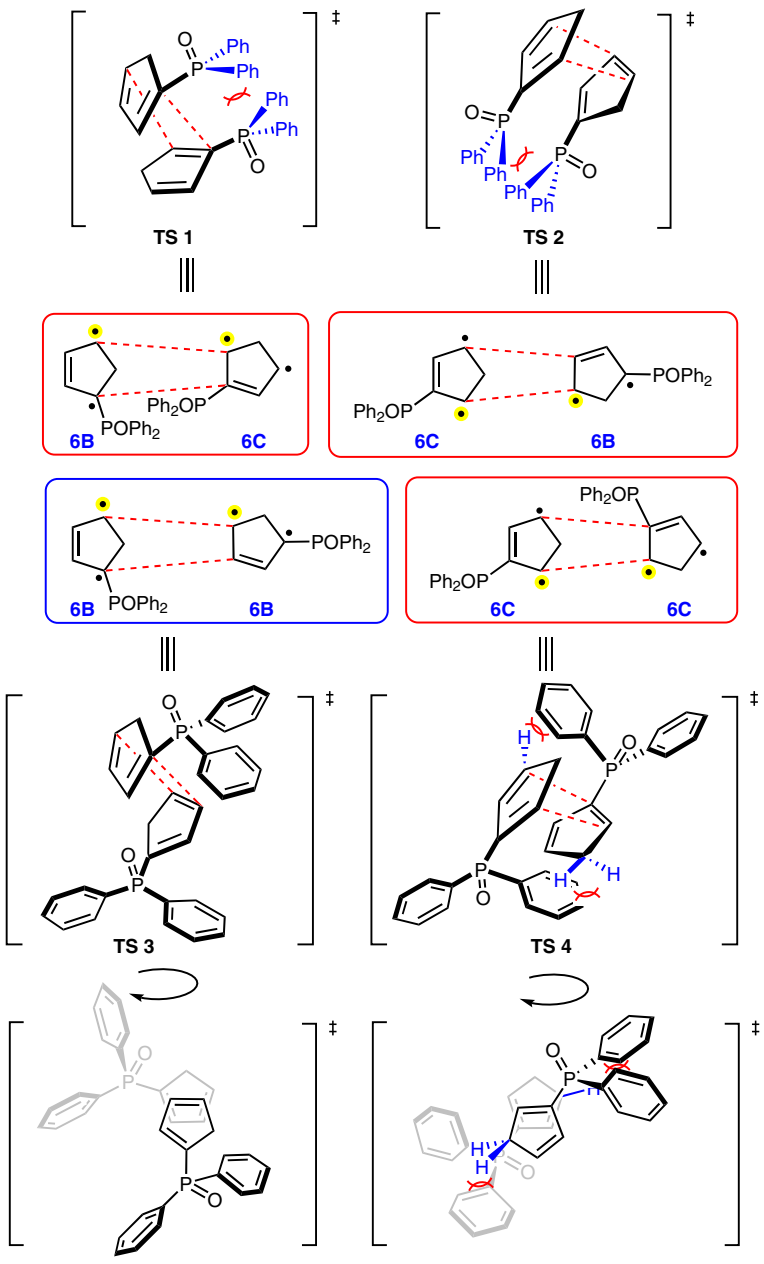

Figure 1 Electronically favoured combinations for the formation of possible phosphine oxide dimers, and their transition states. Yellow highlighting indicates the least stabilized radical for each structure. Transition states were approximated through observations of plastic models.

dict the observed product 7a among the 25 possible outcomes for the dimerization of $\mathbf{6}$ ( 16 possible outcomes if the participation of $\mathbf{6 A}$ is discounted at the outset) - an impressive feat considering that this is the first time that a noncanonical Thiele product has been fully rationalized by any conceptual model.

We repeated the reaction in Scheme 2 using the smaller dimethylphosphinic chloride (5b) as the electrophile, and found that an analogous product ( $\mathbf{7 b}$ ) was obtained as the only isolable species. Thus, the tetrahedral geometry of the phosphine oxide is apparently sufficient to bias the reactivity, notwithstanding the smaller size of the methyl substituent relative to phenyl. Searching the literature, we also uncovered a similar reaction reported by Bridges and Fisher for the dimerization of sulfonylated cyclopentadienes to afford the bis-sulfone $\mathbf{9}$ in $55 \%$ as a single regioisomer 
(Scheme 3). ${ }^{18}$ Once again, the tetrahedral nature of the electron-withdrawing group may guide the reaction through TS3 in preference to the canonical TS2 transition state.



Scheme 3 Bridges' synthesis of bissulfonylated dicyclopentadiene 9

Thus far, we have shown that one should be able to correctly predict the regiochemical outcome of the dimerization of monosubstituted cyclopentadienes through a combination of the radical stabilization algorithm described here and simple steric arguments. In order to further test the reliability of this model, we next considered an even more complex system. In 1986, Kämpchen and co-workers reported a dimerization of bis-sulfonyl cyclopentadienes $\mathbf{1 0}$ to afford the tetrakis-sulfonyl dicyclopentadiene $\mathbf{1 1}$ (Scheme 4 ) in $72 \%$ yield. $^{19}$

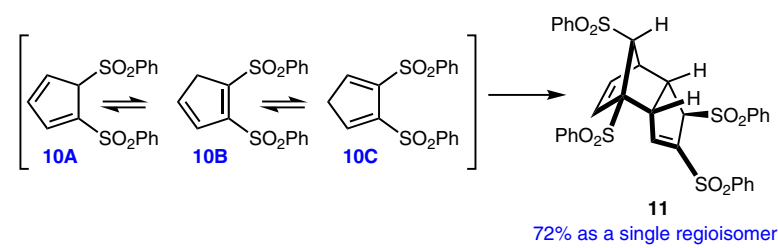

Scheme 4 Kämpchen's synthesis of tetrasulfonylated dicyclopentadiene 11

Because we had no information about the relative abundances of intermediates $10 \mathrm{~A}, \mathbf{1 0 B}$, and 10C, we simply listed all 25 possible pairings (see Supporting Information Figure S5 for details). After matching the least stable radical centre (as identified by the algorithm) from each monomer, and discarding those combinations that would lead to obvious steric clashes (see Supporting Information Figures S5 and S6), we were left with four reasonable trajectories for the reaction (TS5, TS6, TS7, and TS8 in Figure 2).

While TS5, TS6, and TS8 each have at least one pair of phenyl rings which would unfavourably interact with one another, TS7 suffers comparatively less steric crowding. This would therefore be the expected pathway for the reaction to follow. Indeed, the predicted regiochemistry for the reaction once again coincides with the observed product.

To the best of our knowledge, compounds $\mathbf{7 a}, \mathbf{7 b}, \mathbf{9}$, and $\mathbf{1 1}$ are the only known noncanonical Thiele-type homodimerization products. However, other monosubstituted products are known, which arise from heterodimerization of carboxylated cyclopentadienes $\mathbf{4}$ with unsubstituted
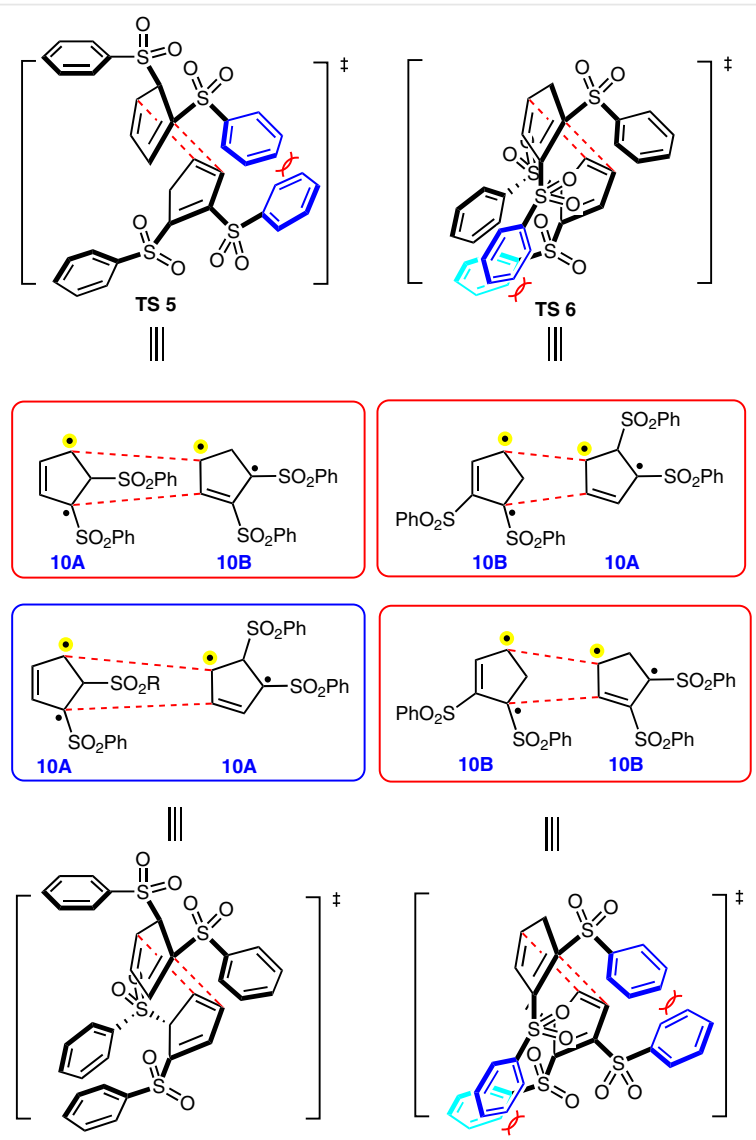

TS 7



TS 8

Figure 2 Electronically favoured combinations for the formation of tetrakis-sulfonyl dicyclopentadienes and their transition states. Yellow highlighting indicates the least stabilized radical for each structure. Transition states were approximated through observations of plastic models.

cyclopentadiene. These 'half-Thiele' compounds $\mathbf{1 2}$ and $\mathbf{1 3}$ (Scheme 5) were initially reported by Peters, ${ }^{20}$ and were recently used by our group as precursors of functionalized polydicyclopentadiene materials. ${ }^{4 \mathrm{~b}}$

As a final test for the validity of the radical stabilization algorithm developed herein, we drew out the eight possible pairings for cyclopentadiene with either $\mathbf{4 B}$ or $\mathbf{4 C}$, once again discounting $\mathbf{4 A}$ since it is absent from the reaction mixture (Scheme 5).

Since cyclopentadiene itself is symmetric, we need only identify in this case which prospective couplings involve the alignment of the least stabilized radical of the $\mathbf{4 B}$ or $\mathbf{4 C}$ resonance structure to one of the terminal radicals of the cyclopentadiene diradical. Five possible pairings fulfil this criterion (circled in Scheme 5). Of these, three would involve the creation of quaternary centres, and so the transition states for these pairings (circled in red) would be expected to be somewhat higher in energy than those for the other two possibilities. Considering both electronic and 

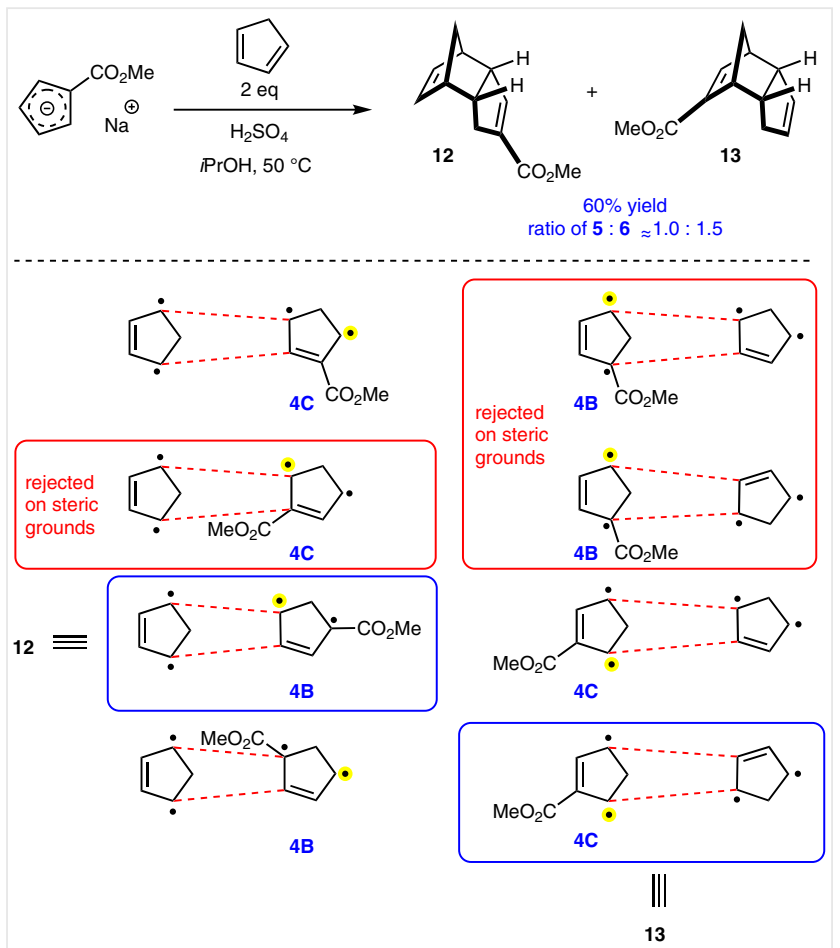

Scheme 5 'Half-Thiele ester' synthesis and predictions by radicalstabilization logic. Yellow highlighting indicates the least stabilized radical for each structure.

steric effects, then, one would anticipate the two pairings circled in blue to be the most productive. Once again this is borne out by the isolated products, since one of the two predicted heterodimerizations would lead to compound 12 while the other would afford compound 13.

In summary, we have described the first synthesis of phosphine oxide containing Thiele acid analogues ( $\mathbf{7 a}$ and 7b) and shown through rigorous spectroscopic analysis that these species are regiochemically dissimilar from the usual major products arising from dimerization of cyclopentadienes bearing electron-withdrawing groups (e.g., 1a and 1b). We have further shown that these outcomes, together with other unusual homo- and heterodimerizations reported in the literature (leading to $\mathbf{9}, \mathbf{1 1 - 1 3}$ ) can be easily rationalized using radical stabilization arguments that follow logically from those advanced by Dewar ${ }^{11}$ and Deslongchamps, ${ }^{8}$ together with simple steric considerations (see Figure $\mathrm{S} 7$ for a graphical illustration of the complete prediction algorithm). The success of these simple methods - requiring no intensive calculations - in rationalizing the outcomes for such complex cycloadditions is quite remarkable and we hope that our results will stimulate further discussion among other groups as to their validity in predicting the outcomes of challenging Diels-Alder reactions. Although Deslongchamps and Deslongchamps have argued that radical-based predictive methods have general applicability across most simple Diels-Alder reactions, ${ }^{8}$ and we have shown here their utility in correctly rationalizing the outcomes of complex dimerizations that were not wellknown at the time of the Deslongchamps and Dewar publications, it is still of course possible that the method will fail for other systems. Additionally, we should stress that one substantial current limitation to the algorithm discussed here is its inability to rationalize which product will form in greatest abundance. For example, the model correctly identifies the formation of compounds 1-3 over the other 13 possible outcomes, but does not satisfactorily address the relative ratios of the three observed products. Similarly, the model fails to adequately account for the predominance of half-Thiele product $\mathbf{1 3}$ over the related structure 12. This distinction is particularly relevant to our polymer synthesis efforts, since $\mathbf{1 2}$ is a valuable monomer for ring-opening metathesis polymerization (ROMP) while $\mathbf{1 3}$ is not. ${ }^{4 \mathrm{~b}}$

From a synthetic planning perspective, we are encouraged to note that simple radical stabilization appears to be valuable in predicting the outcomes of complex reactions. But we leave it for others to debate whether or not these results necessarily imply the existence of diradical (or diradicaloid) character in the Diels-Alder transition state, or whether 'radical stabilization' merely functions as a convenient proxy for some other property (e.g., unanticipated FMO coefficient contributions, subdominant orbital interactions, ${ }^{21}$ paralocalization energy, ${ }^{22}$ etc.) that may be important in governing the reaction outcome.

\section{Funding Information}

This work was supported by the National Science and Engineering Research Council of Canada (NSERC), and by the Michael Smith Foundation for Health Research.

\section{Acknowledgment}

JW acknowledges salary support from the Canada Research Chairs program.

\section{Supporting Information}

Supporting information for this article is available online at https://doi.org/10.1055/s-0036-1588583.

\section{References and Notes}

(1) (a) Corey, E. J. Angew. Chem. Int. Ed. 2002, 41, 1650. (b) Nicolaou, K. C.; Snyder, S. A.; Montagnon, T.; Vassilikogiannakis, G. Angew. Chem. Int. Ed. 2002, 41, 1668. (c) Diels, O.; Alder, K. Justus Liebigs Ann. Chem. 1928, 460, 98.

(2) (a) Blackman, M. L.; Royzen, M.; Fox, J. M. J. Am. Chem. Soc. 2008, 130, 13518. (b) Inglis, A. J.; Sinnwell, S.; Stenzel, M. H.; BarnerKowollik, C. Angew. Chem. Int. Ed. 2009, 48, 2411. (c) Laure, C. B.; Marion, R.; Marie-Helene, L. Curr. Org. Chem. 2016, 20, 2358.

(3) Marchand, A. P.; Zhao, D.; Ngooi, T.-K.; Vidyasagar, V.; Watson, W. H.; Kashyap, R. P. Tetrahedron 1993, 49, 2613. 
(4) (a) Murphy, E. B.; Bolanos, E.; Schaffner-Hamann, C.; Wudl, F.; Nutt, S. R.; Auad, M. L. Macromolecules 2008, 41, 5203. (b) Chen, J.; Burns, F. P.; Moffitt, M. G.; Wulff, J. E. ACS Omega 2016, 1, 532. (c) Fleet, E. J.; Zhang, Y.; Hayes, S. A.; Smith, P. J. J. J. Mater. Chem. A 2015, 3, 2283.

(5) Chen, J.; Sun, X.; Oliver, A. G.; Wulff, J. E. Can. J. Chem. 2016, 95, 234.

(6) Chen, J.; Kilpatrick, B.; Oliver, A. G.; Wulff, J. E. J. Org. Chem. 2015, 80, 8979.

(7) (a) Fleming, I. Frontier Orbitals and Organic Chemical Reactions; John Wiley and Sons: Chichester, 1976, 136 and 167. (b) Fleming, I. Molecular Orbitals and Organic Chemical Reactions, Reference Edition; John Wiley and Sons: Chichester, 2010, 321.

(8) Deslongchamps, G.; Deslongchamps, P. Tetrahedron 2013, 69, 6022.

(9) Chen, J.; Wulff, J. E. Org. Biomol. Chem. 2016, 14, 10170.

(10) We acknowledge that it seems paradoxical (and perhaps mechanistically indefensible) to evaluate the delocalization-dependent stability of resonance structures which must by definition be electronically restricted. But the algorithm described in Figure S7 nonetheless provides some useful measure of which centers would be more acomodating of any spin density which might exist in the transition state.

(11) Dewar, M. J. S.; Olivella, S.; Stewart, J. J. P. J. Am. Chem. Soc. 1986, 108,5771

(12) Staroverov, V. N.; Davidson, E. R. J. Am. Chem. Soc. 2000, 122, 186.

(13) Firestone, R. A. J. Org. Chem. 1972, 37, 2181.

(14) Liu, Y.; Spingler, B.; Schmutz, P.; Alberto, R. J. Am. Chem. Soc. 2008, 130, 1554.

(15) Typical Procedure for the Synthesis of 7a

A flame-dried round-bottom flask under argon atmosphere was charged with diphenylphosphinic chloride (236 mg, $1 \mathrm{mmol}$ ) and THF ( $3 \mathrm{~mL}$ ). To this solution was added sodium cyclopentadienylide ( $2 \mathrm{M}$ in THF, $1 \mathrm{mmol}$ ) at $0{ }^{\circ} \mathrm{C}$ with stirring. After 30 min, the reaction was quenched by water, extracted with $\mathrm{CH}_{2} \mathrm{Cl}_{2}$, and dried over $\mathrm{MgSO}_{4}$. After the removal of solvent, the neat mixture was heated to $50{ }^{\circ} \mathrm{C}$ overnight. The resulting deep purple mixture was loaded onto a silica gel column and eluted with $\mathrm{CH}_{2} \mathrm{Cl}_{2} / \mathrm{MeOH}$ (20:1 to 10:1) to give 7a as a brown oil (159 $\mathrm{mg}, 60 \%) .{ }^{1} \mathrm{H}$ NMR $\left(500 \mathrm{MHz}, \mathrm{CDCl}_{3}\right): \delta=7.80-7.84(\mathrm{~m}, 2 \mathrm{H})$, 7.71-7.77 (m, 2 H), 7.47-7.59 (m, 7 H), 7.33-7.47 (m, 7 H), 7.29 (td, J = 7.7, 2.7 Hz, $2 \mathrm{H}), 6.19-6.24(\mathrm{~m}, 2 \mathrm{H}), 5.38(\mathrm{dd}, \mathrm{J}=10.5,2.0$ $\mathrm{Hz}, 1 \mathrm{H}), 3.91-3.97(\mathrm{~m}, 1 \mathrm{H}), 3.06-3.10(\mathrm{~m}, 1 \mathrm{H}), 2.97-3.03$ ( $\mathrm{m}, 1$ H), 2.50 (ddd, J = 17.6, 10.4, $1.7 \mathrm{~Hz}, 1 \mathrm{H}), 1.89$ (d, J = $17.6 \mathrm{~Hz}, 1$ $\mathrm{H}), 1.85(\mathrm{dd}, \mathrm{J}=8.7,1.7 \mathrm{~Hz}, 1 \mathrm{H}), 1.68(\mathrm{~d}, \mathrm{~J}=8.7 \mathrm{~Hz}, 1 \mathrm{H}) .{ }^{13} \mathrm{C}$ $\operatorname{NMR}\left(125 \mathrm{MHz}, \mathrm{CDCl}_{3}\right): \delta=146.5(\mathrm{~d}, \mathrm{~J}=12.9 \mathrm{~Hz}), 140.6(\mathrm{~d}, \mathrm{~J}=$ $99.5 \mathrm{~Hz}), 135.4(\mathrm{~d}, \mathrm{~J}=11.2 \mathrm{~Hz}), 133.7(\mathrm{~d}, \mathrm{~J}=4.7 \mathrm{~Hz}), 132.6$ (d, J = $86.6 \mathrm{~Hz}), 132.2-131.2(\mathrm{~m}), 128.6-128.4(\mathrm{~m}), 58.1(\mathrm{~d}, \mathrm{~J}=16.2$ $\mathrm{Hz}), 57.7(\mathrm{~d}, \mathrm{~J}=87.7 \mathrm{~Hz}), 52.6,46.9(\mathrm{~d}, \mathrm{~J}=13.9 \mathrm{~Hz}), 43.7(\mathrm{dd}, \mathrm{J}=$ 9.4, $5.6 \mathrm{~Hz}), 34.7(\mathrm{~d}, \mathrm{~J}=11.2 \mathrm{~Hz}) .{ }^{31} \mathrm{P}$ NMR $\left(202 \mathrm{MHz}, \mathrm{CDCl}_{3}\right): \delta=$ 29.9, 23.6. IR (film): 3056, 2929, 1607, 1436, 1176, $1116 \mathrm{~cm}^{-1}$. ESI-HRMS: $m / z$ calcd for $[\mathrm{M}+\mathrm{Na}]^{+} \mathrm{C}_{34} \mathrm{H}_{30} \mathrm{O}_{2} \mathrm{P}_{2} \mathrm{Na}$ : 555.1613; found: 555.1612.

(16) (a) Black, K.; Liu, P.; Xu, L.; Doubleday, C.; Houk, K. N. Proc. Natl. Acad. Sci. 2012, 109, 12860. (b) Wannere, C. S.; Paul, A.; Herges, R.; Houk, K. N.; Schaefer, H. F.; Von Ragué Schleyer, P. J. Comput. Chem. 2007, 28, 344.

(17) Consideration of plastic models reveals that the vinyl protons in TS3 suffer no significant interactions with each other, or with the backbone carbon atoms.

(18) Bridges, A. J.; Fischer, J. W. J. Chem. Soc., Perkin Trans. 1 1983, 2359.

(19) Hartke, K.; Jung, M. H.; Zerbe, H.; Kämpchen, T. Liebigs Ann. Chem. 1986, 1986, 1268.

(20) (a) Peters, D. J. Chem. Soc. 1961, 1037. (b) Alder, K.; Flock, F. H.; Hausweiler, A.; Reeber, R. Chem. Ber. 1954, 87, 1752.

(21) Spino, C.; Pesant, M.; Dory, Y. Angew. Chem. Int. Ed. 1998, 37, 3262.

(22) Spino, C.; Crawford, J.; Cui, Y.; Gugelchuk, M. J. Chem. Soc., Perkin Trans. 2 1998, 1499. 